\title{
Reflexões e territórios em contínua mutação
}

\section{Reflections and territories on continuous mutation}

\author{
Alan Ripoll Alves ${ }^{1}$ \\ Marcelo Limont ${ }^{2}$ \\ Rodrigo Arantes Reis ${ }^{3}$
}

\section{Introdução}

O presente dossiê da Guaju - Revista Brasileira de Desenvolvimento Territorial Sustentável é oriundo, em grande parte, de artigos que foram selecionados durante o II Simpósio Brasileiro de Desenvolvimento Territorial Sustentável (II SBDTS), realizado nos dias 08, 09 e 10 de novembro de 2017, no Setor Litoral da Universidade Federal do Paraná (UFPR Litoral), localizado no município de Matinhos-PR.

O II SBDTS ocorreu em uma região considerada um dos maiores hotspots de biodiversidade do planeta, correspondendo a um dos últimos remanescentes contínuos de Floresta Atlântica costeira do Brasil e ainda relativamente conservada, ao mesmo tempo em que representa uma região economicamente vulnerável no âmbito do Estado do Paraná, paradoxalmente o maior exportador de soja do Brasil e, consequentemente, do mundo em termos de produção/área (DEAN, 1996; TIEPOLO; DENARDIN, 2016). Este contraste gerado a partir da influência portuária, pressão turística, especulação imobiliária, dentre outros fatores, faz com que produtores da agricultura familiar, comunidades tradicionais que vivem à base da pesca artesanal e outros componentes típicos do Litoral do Paraná se coloquem à margem de um processo voraz de crescimento, que se manifesta sob formas socioambientalmente degradadoras (ANDRIGUETTO FILHO, 1999; ESTADES, 2003).

Essa complexidade de relações sociais e ambientais singulares, intrínsecas ao bioma Mata Atlântica, consistiu em um dos fatores motivadores do evento, o qual teve como objetivo principal a divulgação de pesquisas e o intercâmbio de experiências interdisciplinares sobre temáticas ligadas ao Desenvolvimento Territorial Sustentável (DTS). Participaram do simpósio cerca de 400 docentes,

\footnotetext{
${ }^{1}$ Biólogo e pós-doutorando pelo Programa de Pós-Graduação em Desenvolvimento Territorial Sustentável (PPGDTS) da UFPR Litoral. E-mail: alanripoll@gmail.com

${ }^{2}$ Biólogo, professor do Programa de Pós-Graduação em Gestão Ambiental (PPGAmb) da Universidade Positivo. E-mail: marcelo.limont@up.edu.br

${ }^{3}$ Biólogo, professor do Programa de Pós-Graduação em Desenvolvimento Territorial Sustentável (PPGDTS) da UFPR Litoral. E-mail:reisra@gmail.com
} 
pesquisadores, estudantes de graduação e pós-graduação, e profissionais de diversas áreas, provenientes de 12 estados do Brasil, além de países como a Alemanha, Argentina, Chile, Colômbia, Costa Rica, México e Peru.

A programação do evento contou com a apresentação de trabalhos (resultados de pesquisa e extensão) com interface às temáticas fundantes do Programa de Pós-Graduação em Desenvolvimento Territorial Sustentável (PPGDTS), responsável pela sua organização, representadas essencialmente pelos eixos temáticos: a) Socioeconomia e Saberes Locais; b) Redes Sociais e Políticas Públicas; e c) Ecologia e Biodiversidade. Com base nestes pilares que alguns dos artigos trazidos ao II SBDTS, alicerçados de forma concisa em abordagens interdisciplinares, foram selecionados, de modo a permitir ao(à) leitor(a) desta publicação o acesso a um conteúdo de elevada qualidade e contemporâneo na esfera do DTS no Brasil e no mundo.

No bojo das convergências apresentadas pelos artigos desta edição, decidiu-se por organizar este número em três momentos, orientados pelos encadeamentos evidenciados nos textos, apesar de suas condições de independência.

\section{A necessidade de um (re)desenvolvimento territorial adaptado}

Transcorridas cerca de duas décadas do novo milênio, a sociedade humana vem se deparando com um cenário em permanente modificação. Falar em avanços e retrocessos neste âmbito é quase tão arriscado quanto escolher um referencial para comparar os dias atuais com o que acabou virando passado.

Tornou-se praxe no pensamento ocidentalizado adotar o que se poderia denominar de parâmetros de mensuração de desenvolvimento. Um exemplo claro de como isso acontece se daria pela nomenclatura que continuamente foi se metamorfoseando, no sentido de satisfazer a um eufemismo estratégico de dominação, embora a realidade continuasse mantendo as diferenças presentes desde o início dessa arbitrária segmentação: de países de primeiro, segundo e terceiro mundo (como se o "mundo" pudesse ser de fato fracionado!) se passou a ter nações desenvolvidas e subdesenvolvidas, ou as do "Norte" e do "Sul", relevando-se algumas exceções a estas "coordenadas" geopoliticamente atribuídas; para, em seguida, os países começarem a ser grosso modo distinguidos em desenvolvidos ou em desenvolvimento; de maneira que hoje se empregue mais comumente os termos países de economia avançada e de economia em crescimento, limitando o já questionável conceito de desenvolvimento ao aspecto estritamente econômico (SANTOS, 1997; SASSEN, 2010). 
Em uma extensão do processo de colonização - e aqui se mostraria prudente falar em neocolonização -, que perdura por séculos sobre algumas nações, como é o caso do Brasil, a reprodução dessa desigualdade vista a partir de certos ângulos se revela mais do que pertinente para assegurar a soberania de poucos ante a múltiplos dominados. Seja por intermédio de errôneos ou parciais registros históricos seja pela inoculação forçada de valores culturais e religiosos, bem como preceitos de outra natureza, a ocidentalização tem sido um dos grandes males a assolar o planeta, e quando se pensa na mesma é quase que imediata a sua associação com os EUA.

Até mesmo os países que impuseram relativa resistência ao modo de produção e viver norteamericano acabaram ruindo com o tempo (RODRIGUEZ; SILVA, 2016) - e talvez a última das vítimas tenha sido a Coreia do Norte, mais recentemente (HABIB, 2018). A disseminação dessa influência se consolidou a tal ponto que chegou a se tornar arraigada à organização de alguns povos, em sobreposição a elementos muitas vezes tidos como essenciais às suas identidades, submetendo-os à dominação e consequente inferiorização em suas próprias origens, conduzindo-os a um novo perfil, cunhado à vontade do agente dominador.

A propagação da "cultura de dominação", com o passar do tempo, vem se mostrando tentadora e pareceu ter também afetado o que poderia ser neste contexto ressignificado como nações "subjugadas" ou "oprimidas" (FREIRE, 1970). Esta conformação gerada, por sua vez, ironicamente passou a realizar o mesmo internamente - uma "auto-dominação", assim como uma dominação dos próprios "subjugados" sobre outros povos em condições mais fragilizadas do que as suas. E esta submissão vem ocorrendo sob várias escalas, entre as práticas de produção mais tradicionais - como a agricultura, a pesca e o trabalho artesanal, por exemplo - até outras que se constituíram por intermédio da tecnologia e reformulação do Estado, de tal maneira que não se mostrasse possível discutir um modo de dominação em específico, já que não existiria uma homogeneidade ou lógica por detrás desse processo, o qual ultrapassa os conceitos tradicionais de território e incita novas releituras.

A compreensão do desenvolvimento territorial na pós-modernidade requer pensar em componentes inéditos, que sejam frutos de uma realidade em fermentação, de problemáticas que se perpetuam e não encontram (ou não se pretende propositalmente) solução e outros desafios que exigem maleabilidade e a emergência de olhares que devem acompanhá-los em torno de perspectivas futuras (HALL, 2006). A noção de território, como um propágulo dessa reflexão, consequentemente não pode se restringir a seus limites físicos, naturais e geopolíticos, passando a exigir por interpretações acerca dos arranjos sociais e institucionais, que lhe conferem uma identidade historicamente construída (ABRAMOVAY, 2000; RODRIGUEZ; SILVA, 2016). 
Nesse contexto dinâmico de apropriação conceitual e empírica da dimensão territorial, a evolução da linguagem, a velocidade de comunicação, os mecanismos de segurança, a preservação da privacidade, a possibilidade de visualização expandida do território físico por intermédio de recursos contemporâneos, entre outras manifestações, correspondem a sinais de uma era que está ainda se desenhando.

\section{As multifaces de um território em permanente descobrimento}

A (in)evolução da sociedade no decorrer dos tempos tem sido impulsionada por ideais utópicos que tem possibilitado, dentro de uma visão restrita, os chamados avanços para além de suas épocas, quando, na realidade, dever-se-ia esperar com maior naturalidade a descoberta, a modificação do que parecia imutável, e a materialização dos sonhos. No entanto, a ausência ou o desestímulo dessas "ambições" inerentes à espécie humana, em parte, vem se revelando justificável pelas discrepâncias intencionalmente criadas e fomentadas entre as sociedades e no interior das mesmas, obedecendo a um rigor sistemático de organização.

A América Latina, em meio à desnutrição sofrida nos períodos colonial e neocolonial, é a prova de que apesar de todas as adversidades às quais é submetida até o presente, reúne recursos potenciais necessários para avançar científica e tecnologicamente de forma comparável às nações vistas como mais privilegiadas nesses aspectos. No entanto, no que compete à produtividade de determinados bens, como os de consumo de alimentos, por exemplo, ela está predominantemente à frente da maior parte do planeta. Se estes paralelos fossem estendidos à diversidade demográfica, aos valores socioculturais nela construídos e à contribuição que os mesmos integralmente têm fornecido para o enriquecimento da humanidade, observar-se-ia que a sua importância vem sendo subestimada, inclusive pelos seus próprios integrantes, em sua maioria retidos no que se poderia chamar de "redoma da pequenez". A conversão deste potencial oculto em realidade, por sua vez, necessita ultrapassar a dimensão da materialidade, a fim de romper as estruturas de atraso em que se encontram ancorados os privilégios dos grupos tradicionais dominantes, os quais parecem residir mais na mente humana do que nas condições externas propriamente ditas (HERRERA, 1975; THEIS, 2015).

A distinção do rural e do urbano destaca muitas das relações de poder que formatam as experiências de pessoas de quase todas as culturas. Sem surpresas, então, muitas atividades culturais operam para manter as pessoas nos seus lugares, mesmo diante dos deslocamentos demográficos e econômicos globais, como a migração do rural para o urbano e a industrialização. Consequentemente, 
essa segregação significa muito mais poder do que as aparências físicas sugerem; habitantes de áreas onde as cidades e o interior parecem quase indistinguíveis podem, entretanto, gerar uma diferença através do discurso cultural extensivo (CHING; CREED, 1997).

Enquanto um dos desdobramentos mais representativos do desenvolvimento industrial no Brasil, após os anos 1970, consistiu na intensificação da concentração de renda ${ }^{4}$, no agravamento das condições de moradia e no alcance de índices preocupantes de subnutrição, no panorama das comunidades rurais foi possível verificar alguns esforços de desmontagem de sistemas historicamente estruturados, possibilitando a formação de focos de resistência às forças hegemônicas atuantes (PAULA, 2017).

Alternativas errantes em contraposição a um processo de dominação que se alastra há séculos na produção agrícola global têm ocorrido tardiamente, porém, ainda com chances de reverter o quadro atual, mesmo com a magnitude das gerações que vêm sendo por ele assoladas em todo o mundo. Entretanto, as dúvidas pairam na complexidade em que se encontra dissolvida essa problemática: de uma escala pequena, bastante específica, a um macrorreferencial, de ordem mundial, denota-se que situações relativamente parecidas e não raro relacionadas se difundem, suscitando questionamentos sobre até que estágio a espécie humana poderá se manter conectada, comungando de suas maiores conquistas, como também dos piores desastres por ela ocasionados, enquanto apenas uma minoria se faz beneficiada. Outro ponto para se analisar parcialmente essa situação, que se difrata em incontáveis feixes, surge através da interpretação do que se convencionou economicamente nomear de recursos naturais ao invés de bens ou patrimônios naturais, por exemplo, que levou à formação de um pensamento estrito em detrimento de uma compreensão holística dos elementos naturais.

Logo, a dinâmica que vem ocorrendo por intermédio da destruição de florestas nativas, por motivos diversos, pode denunciar a parcimônia de um povo, a sua falta de altruísmo e de prestar sua previdência, ainda que aparentes proteções tenham sido pensadas e formalizadas, como as quase seculares leis votadas e condensadas nos códigos florestais brasileiros, incluindo as do Estado do Paraná, consideradas até qualificadas sob certos aspectos teóricos, todavia, constituindo-se em letras mortas diante do que se observa na prática (HOEHNE, 1930; BERTÉ, 2009). Em se tratando do bioma Mata Atlântica, existe uma legislação específica (Lei n. 11.428/2006 e seu Decreto n. 6.660/2008), cuja criação representa o viés máximo do ordenamento territorial, pautado

\footnotetext{
$440 \%$ dos mais pobres detinham apenas $13 \%$ da riqueza do país em 2012, ao passo que os $10 \%$ mais ricos acumulavam $42 \%$ da riqueza total do Brasil (PAULA, 2017).
} 
majoritariamente em instrumentos legalistas de comando e controle que, contudo, não dispõem de uma estrutura institucional adequada de gestão pública a ponto de garantir sua eficaz aplicação.

A evolução da agricultura nômade, passando pela campesina, dentre outras várias formas de organização, até se chegar no que atualmente se concebe como sistema agroalimentar se trata de um dos fenômenos que esteve ligado à dizimação florestal e, consequentemente, alteração irreversível do território em suas infinitas concepções (PAULA, 2017).

Com o crescente engajamento das estruturas produtivas locais aos mercados globais, em um progressivo distanciamento dos princípios clássicos das vantagens comparativas, seguindo um fluxo que tende à universalização e homogeneização do consumo, e à internacionalização dos capitais mediada por corporações e pelo Estado, renegando a participação de pequenos grupos fundados em organizações próprias, a humanidade vem sendo conduzida à debilitação da produção alimentar e à perda da identidade local, gerando dependências e deformações nas relações de trabalho, no abastecimento alimentar, nas ligações materiais homem-alimento e nos ambientes familiares (PELLING, 1967; MAX-NEEF; ELIZALDE; HOPENHAYN, 1993; SACHS, 2007).

Em reação a essa ordem nebulosamente configurada, movimentos clamando por independência e espaço para se trabalharem caminhos paralelos, como os propostos pela economia solidária, agroecologia, permacultura, turismo de base comunitária, ciência indígena, ciência cidadã e ciência do futuro, apenas para citar alguns exemplos, paulatinamente vêm se adensando com o desenvolvimento de estudos neles fundamentados, favorecendo a maior aplicabilidade e divulgação não somente científica, como em outras plataformas, ao elevar as expectativas pela solidificação de referenciais tão acessíveis quanto os apresentados pelos sistemas hoje predominantes (SCHMIDT; STOLTZ, 2006; BUSSEY, 2014; SOUZA et al., 2016).

Um dos resultados desse processo é que a temática do DTS vem se (re)estruturando como um percurso maleável ao diálogo e ao intercâmbio de experiências entre diferentes atores e áreas de conhecimento, pautando-se na quebra de uma rede hierarquizada de produção, organização e transmissão de saberes, em que a integração de ecotécnicas de base científica possa se tornar capaz de resgatar o "saber fazer" das populações presentes nos territórios, fortificando o pluralismo tecnológico, base da educação para o ecodesenvolvimento (VIEIRA, 2002).

A partir desse amplo cenário o II SBDTS se lançou como um pequeno passo objetivando preencher uma lacuna no campo da pesquisa e do desenvolvimento na América Latina, que ocorre não por motivos quantitativos, mas pelo seu descolamento da realidade latino-americana per se (HERRERA, 1975). A construção de estratégias que permitam às comunidades e populações marginalizadas acessarem instrumentos que lhes facilitem uma participação real nos processos de 
decisão e gestão dos territórios e reivindicar seus direitos é uma das bases da Cidadania Científica (SACHS, 1995), prezada pelo SBDTS em sua formação.

\section{O florescimento de novos debates}

Este dossiê possui uma composição marcadamente eclética, o que de algum modo reflete o que foi o II SBDTS, no qual nove diferentes grupos de trabalho trataram de linhas de pensamento relacionadas ao DTS, a saber: (I) Socioeconomia: Princípios Teóricos e Estudos de Caso; (II) Recursos e Dinâmicas Territoriais para o Desenvolvimento Local; (III) Turismo, Território e Desenvolvimento; (IV) Estudos em Redes Sociais; (V) Saúde, Sociedade e Desenvolvimento; (VI) Políticas Públicas e Desenvolvimento Territorial Sustentável; (VII) Indicadores Ambientais e Gestão do Território; (VIII), Biodiversidade, Bioprospecção e Uso dos Recursos Naturais; e (IX) Gestão de Unidades de Conservação e Sociobiodiversidade.

O primeiro artigo, intitulado $O$ trabalho artesanal: cultura e pertencimento ao local, abre um momento desta edição que visa a discutir, do ponto de vista teórico, as relações entre os conceitos de cultura e economia a partir do trabalho artesanal. Referendado em concepções históricas, o texto explicita o papel de promoção da lógica de subsistência de comunidades locais e a valorização do território enquanto ferramenta de pertencimento, ambos sustentados no ideário do trabalho artesanal.

O segundo artigo, Economia solidária e agroecologia: juventude camponesa e projetos produtivos em assentamentos de reforma agrária, dá sequência à discussão sobre as alternatividades de práticas produtivas, no caso, guiada pelos princípios da Economia Solidária e da Agroecologia. O texto explicita ainda as potencialidades e as dificuldades dos jovens agricultores assentados em garantir o desenvolvimento e, principalmente, a continuidade de projetos produtivos que valorizem ações na esfera da emancipação social da juventude camponesa e sua permanência no campo.

O terceiro artigo, Dinâmicas dos sistemas agrários nos territórios Mapuche de Araucanía Costera, Chile, amplia a escala territorial no contexto da América Latina e trata do desenvolvimento da agricultura em quatro períodos - indígena, pré-colonial, colonial e atual, destacando a tendência de monocultivo em substituição à variedade de culturas, outrora predominantes.

$\mathrm{O}$ quarto artigo, Turismo de base comunitaria y redes a escala humana: principios para pensar una autocertificación para el turismo indígena, apropria-se da teoria do Desenvolvimento à Escala Humana para referendar a modalidade de turismo de base comunitária, aquela que valoriza o protagonismo de sujeitos sociais locais. A experiência empírica é apoiada em um estudo de caso do Sul do Chile, que versa sobre propostas de autocertificação para o turismo indígena. O trabalho 
descreve ainda as principais etapas do processo de certificação em comunidades Mapuche, correspondendo a um processo de referência na área em todo o planeta.

A partir de análise qualitativa de questionários aplicados aos turistas, o artigo Polo Parque dos Lençóis Maranhenses: uma investigação sobre o grau de atratividade do município de Barreirinhas e comunidades visa a identificar o grau de atratividades dos povoados próximos ao Parque Nacional dos Lençóis Maranhenses. Os resultados encontrados demonstraram o potencial desses povoados como atrativo turístico, porém, demandantes de melhorias no atendimento aos turistas e na inclusão social nos roteiros do turismo local.

$\mathrm{O}$ artigo A expansão urbana no entorno do Parque Nacional de Saint-Hilaire-Lange (PNSHL) apresenta as principais alterações de uso da terra e da cobertura vegetal do município de Matinhos entre 2005 e 2016. Foram identificadas diversas áreas no entorno do PNSHL que sofreram alterações dentro do período de análise. No trabalho os autores apontaram a importância do diálogo tanto no processo de elaboração do plano de manejo do parque quanto no de revisão do Plano Diretor para reduzir os usos conflitantes e assegurar os objetivos de conservação do local.

O sétimo artigo, Conflitos ambientais no Litoral Norte do Paraná: um levantamento preliminar, traz uma análise espelhada em dados secundários dos conflitos que ocorrem na região do Litoral do Paraná. No trabalho foram constatados e mapeados oito conflitos que acontecem em cerca de 30 comunidades das 74 observadas na área de estudo.

O trabalho Aplicação da Matriz FPSEEA de Saúde Ambiental para a macrometrópole paulista: subsídios para o planejamento e gestão socioambiental regional aplica a metodologia que utiliza a matriz de indicadores para a saúde socioambiental, denominada Força Motriz-PressãoSituação-Exposição-Efeito-Ações (FPSEEA) para a macrometrópole de São Paulo, no intuito de selecionar indicadores estratégicos nos âmbitos da saúde ambiental e sustentabilidade para a região. Os resultados encontrados mostraram a importância da escala regional como unidade territorial a ser explorada em estudos com este viés.

O estudo Desenvolvimento infantil e sustentabilidade: modelo computacional para representação dos condicionantes do desenvolvimento infantil expõe uma pesquisa de cunho interdisciplinar, aliando ferramentas tecnológicas ao trabalho de campo, registro e interpretação de dados de diferentes campos para se chegar a informações de interesse às políticas públicas.

Integrados, os nove artigos que compõem este dossiê motivam a busca por novas trajetórias, ora reproduzidas de forma similar em distintos territórios ora existentes sob singularidades, o que contribui para mostrar em um pequeno rol que as tentativas de sobreposição e paralelismo entre os territórios se fazem impraticáveis, tendo-se em vista as inúmeras variáveis por eles abarcadas. 


\section{Referências}

ABRAMOVAY, R. O capital social dos territórios: repensando o desenvolvimento rural. Economia Aplicada, v. 04, n. 02, p. 379-397, abr./jun. 2000.

ANDRIGUETTO FILHO, J. M. Sistemas técnicos de pesca e suas dinâmicas de transformação no Litoral do Paraná, Brasil. 242 f. Tese (Doutorado em Meio Ambiente e Desenvolvimento) Programa de Pós-Graduação em Meio Ambiente e Desenvolvimento, Universidade Federal do Paraná, Curitiba, 1999.

BERTÉ, R. Gestão socioambiental no Brasil. Curitiba: Ibpex, 2009. 299 p.

BUSSEY, M. Concepts and effects: ordering and practice in foresight. Foresight, v. 16, n. 01, p. 0116, 2014.

CHING, B.; CREED, G. W. Knowing your place. Rural identity and cultural hierarchy. Nova Iorque e Londres: Routledge, 1997. 277 p.

DEAN, W. A ferro e fogo: a história e a devastação da Mata Atlântica brasileira [Trad. Cid Knipel Moreira; rev. Téc. José Augusto Drummond]. São Paulo: Companhia das Letras, 1996. 484 p.

ESTADES, N. P. O Litoral do Paraná: entre a riqueza natural e a pobreza social. Desenvolvimento e Meio Ambiente, n. 8, p. 25-41, jul./dez. 2003.

FREIRE, P. Pedagogia do Oprimido. 36ª ed. Rio de Janeiro: Paz e Terra, 2003 (1970). 184 p.

HABIB, B. US-North Korea summit agreement is most revealing for what it leaves out. The conversation. Disponível em: < http://theconversation.com/us-north-korea-summit-agreement-ismost-revealing-for-what-it-leaves-out-98094>. Acesso em: 30 jul. 2018.

HALL, S. A identidade cultural na pós-modernidade. $7^{\mathrm{a}}$ ed. São Paulo: DP\&A, 2006. 101 p.

HERRERA, A. O. Ciencia y política en América Latina. 4ª ed. México: Siglo Veinteuno Editores, 1975.

HOEHNE, F. C. Araucarilândia: observações gerais e contribuições ao estudo da flora e fitofisionomia do Brasil. São Paulo: Secretaria da Agricultura, Indústria e Comércio/Melhoramentos, 1930.

MAX-NEEF, M. A.; ELIZALDE, A.; HOPENHAYN, M. Desarrollo a Escala Humana: conceptos, aplicaciones y algunas reflexiones. Montevideo: Nordan-Comunidad; Barcelona: Icaria, 1993. 148 p.

PAULA, N. M. Evolução do sistema agroalimentar mundial: contradições e desafios. Curitiba: CRV, 2017. $226 \mathrm{p}$. 
PELLING, M. The vulnerability of cities: natural disasters and social resilience. Londres: Earthscan Publications, 1967. $211 \mathrm{p}$.

RODRIGUEZ, J. M. M.; SILVA, E. V. Planejamento e gestão ambiental: subsídios da geoecologia das paisagens e da teoria geossistêmica. $2^{a}$ ed. Fortaleza: Edições UFC, 2016. 370 p.

SACHS, I. Em busca de novas estratégias de desenvolvimento. Estudos Avançados, v. 09, n. 25, p. 29-63, 1995.

Rumo à ecossocioeconomia: teoria e prática do desenvolvimento [Org. Paulo Freire Vieira]. São Paulo: Cortez, 2007. 472 p.

SANTOS, M. A natureza do espaço: técnica e tempo. Razão e emoção. $2^{a}$ ed. São Paulo: Hucitec, 1997. $382 \mathrm{p}$.

SASSEN, S. Sociologia da globalização [Trad. Ronaldo Cataldo Costa; rev. Téc. Guilherme G. de F. Xavier Sobrinho]. Porto Alegre: ArtMed, 2010. 240 p.

SCHMIDT, M. A.; STOLTZ, T. (Org.). Educação, cidadania e inclusão social. Curitiba: Aos Quatro Ventos, 2006. 208 p.

SOUZA, C. M. M. et al. (Org.). Novos Talentos - Processos de educação para o ecodesenvolvimento. Blumenau: Nova Letra, 2016. 200 p.

THEIS, I. V. Desenvolvimento científico e tecnológico e território no Brasil. Chapecó-SC: Argos, 2015. $156 \mathrm{p}$.

TIEPOLO, L. M.; DENARDIN, V. F. Desenvolvimento territorial sustentável: uma nova experiência na Mata Atlântica. RBPG, Brasília, v. 13, n. 32, p. 865-888, set./dez. 2016. 